\title{
Study on the Clinical Significance of ACE2 and Its Age-Related Expression
}

\author{
Jie $\mathrm{Gu}^{\mathrm{l}}$ ** \\ JiangWen Yin ${ }^{1, *}$ \\ MengJie Zhang ${ }^{1, *}$ \\ JinHui $\mathrm{Li}^{\prime}$ \\ YeMing $\mathrm{Wu}^{2}$ \\ Jun Chen' \\ HongJun Miao' \\ 'Department of Emergency/Critical care \\ Medicine, Children's Hospital of Nanjing \\ Medical University, Nanjing, Jiangsu \\ Province, 210008, People's Republic of \\ China; ${ }^{2}$ Center of Interventional \\ Radiology and Vascular Surgery, \\ Department of Radiology, Zhongda \\ Hospital, Medical School of Southeast \\ University, Nanjing, Jiangsu Province, \\ 210009, People's Republic of China
}

*These authors contributed equally to this work

Correspondence: Jun Chen; HongJun Miao

Department of Emergency/Critical care Medicine, Children's Hospital of Nanjing Medical University, No. 72 GuangZhou Road, Nanjing, Jiangsu Province, 210008,

People's Republic of China

Tel +86 I38I395I884; +86 I8951769627

Fax +8602583117488

Email chenjundr850@2Icn.com;

drmiaohj16@88.com
Background: ACE2 plays a particular role in the changes in multiple organ functions. However, whether ACE2 expression differs at different ages and whether it plays a role in infection-related organ dysfunction remains unclear.

Methods: Female and male C57BL/6 mice in four different age groups were included in this study. Immunohistochemical and Western blot analyses were performed to evaluate ACE2 expression characteristics in lung tissues. At the same time, we detected the changes of ACE2 in human blood of different ages and evaluated its clinical significance in sepsisassociated organ dysfunction (SAOD).

Results: This study indicated that ACE2 is expressed differently in mouse lung tissues at four different ages $(\mathrm{P}<0.05)$. The peak expression distribution of ACE2 in lung tissues was in the newborn and middle-aged cohorts $(P<0.05)$. Infants younger than one year had a significantly higher concentration of ACE2 in serum and enhanced susceptibility compared with other ages $(\mathrm{P}<0.05)$. Serum APTT, D-dimer, LDH, and PCT, as well as ACE2 in sepsis and SAOD groups, were statistically significant $(\mathrm{P}<0.05)$ and were related to an increased risk of SAOD. There was a positive correlation between ACE2 and D-dimer $(\mathrm{P}<0.05)$.

Conclusion: The levels of ACE2 expression varied in different age groups. It tends to be higher in infants and young children. This result suggests that young children are more susceptible to infection. Moreover, a cutoff value for the ACE2 level $>1551.15 \mathrm{pg} / \mathrm{mL}$ and D-dimer $>984.5 \mathrm{U} / \mathrm{L}$ should be considered a warning sign of infection-associated organ dysfunction and guide the clinician in evaluating the patient's multiple organ function.

Keywords: ACE2, SAOD, infection, organ dysfunction, clinical significance

\section{Introduction}

In previous studies, angiotensin-converting enzyme 2 (ACE2) was shown to be one of the central enzymes of the renin-angiotensin system (RAS), which regulates blood pressure, fluid and electrolyte balance, and vascular tone. ${ }^{1}$ Later studies found that ACE2 played a certain role in the changes in multiple organ functions. For example, ACE2 can protect mice from sepsis-induced acute lung injury. ${ }^{2}$ In patients with aortic stenosis, ${ }^{3}$ elevated plasma ACE2 was a marker of myocardial structural abnormalities and an independent predictor of mortality with an incremental value over traditional prognostic markers. Loss of ACE2 from the myocardium was associated with increased fibrosis and higher circulating ACE2 levels. In addition, the expression of ACE2 in the bronchi and alveoli of diabetic patients increased. $^{4}$

As the COVID-19 pandemic spread around the world, studies found that ACE2 plays an important role in the spread of SARS-CoV-2. SARS-CoV-2 uses ACE2 
when entering host cells. ${ }^{5,6}$ When SARS-CoV-2 enters the respiratory tract, its spike protein binds to ACE2 receptors on the cell surface before advancing into type II alveolar epithelial cells to complete self-replication. ${ }^{7}$ As has been demonstrated, clinical symptoms of SARS-CoV-2 infection vary among individuals. Symptoms include asymptomatic infection, upper- respiratory tract illness, viral pneumonia, respiratory failure, multiple organ dysfunction, and even death. ${ }^{8-10}$ The prevalence and mortality rates of COVID-19 differ between different ages. However, whether ACE2 expression differs at different ages and whether it plays a role in infection-related organ dysfunction remains unclear. Therefore, in this study, we selected the expression of ACE2 in the lung tissue of $\mathrm{C} 57 \mathrm{BL} / 6$ mice of different age groups and detected the changes of ACE2 in human blood of different ages. We then evaluated its clinical significance in sepsisassociated organ dysfunction (SAOD).

\section{Methods Animal Studies}

All animal experiments complied with the National Institutes of Health Guide for the Care and Use of Laboratory Animals (NIH Publications No. 8023, revised 1978). The Institutional Animal Care and Use Committee of Nanjing Medical University gave ethical approval (IACUC-1712016). C57BL/6 mice were purchased from Beijing Weitong Lihua Experimental Animal Technology Co., Ltd. and were reared in the Animal Experimental Center of Nanjing Medical University with free access to food and water. Keeping in mind the general susceptibility to the new coronavirus, this study used 7-day-old, 3-weekold, 8-week-old, and 9-month-old specific pathogen-free (SPF) male and female C57BL/6. These ages are equivalent to the neonatal, childhood, adulthood, and middleaged periods in humans.

\section{Sample Collection}

Mice were euthanized by cervical dislocation, and lung tissues were immediately removed. Parts of the lung tissues were fixed with $4 \%$ paraformaldehyde, and the remaining lung tissues were immediately frozen in liquid nitrogen. After 15 minutes, tissues were removed and stored in a $-80{ }^{\circ} \mathrm{C}$ freezer.

\section{Immunohistochemistry}

The lung tissues of the mice were fixed, embedded in paraffin, sectioned, and dewaxed. After this, they were repaired using citric acid antigen retrieval buffer ( $\mathrm{pH}$ 6.0), and endogenous peroxidase was blocked using 3\% hydrogen peroxide solution. After blocking with BSA, the primary antibody (rabbit polyclonal to ACE2, ab15348) and the secondary antibody (1:250) were incubated. Subsequently, DAB was used for color development. Finally, hematoxylin was used to counterstain the nuclei.

\section{Western Blot}

RIPA protein lysate was used to lyse mouse lung tissue proteins, and protein concentrations were measured using the BCA method; $30 \mu \mathrm{g}$ of the lysate was added to each well and subjected to $8 \%$ SDS-PAGE gel electrophoresis at $75 \mathrm{~V}$ constant pressure for 45 minutes. The mixture flowed to the bottom of the gel to stop electrophoresis, and $300 \mathrm{~mA}$ of continuous current transfer film was applied for 90 minutes. The solution was then blocked with Tris- $\mathrm{HCl}$ buffer (TBST) containing 5\% skimmed milk powder for one hour. Subsequently, ACE2 (1:1000) and GAPDH (1:3000) were diluted with a blocking solution and incubated at $4{ }^{\circ} \mathrm{C}$ overnight. Subsequently, the membrane was washed three times with TBST for ten minutes each time. The secondary antibody (1:2000) was diluted with a blocking solution and incubated at room temperature for one hour. Finally, an electrochemiluminescent detection system was developed to detect the separated protein bands. Using GAPDH as the loading control, the protein bands were analyzed using Image Lab software.

\section{Experimental Subjects and Clinical Subgroup}

From March 2020 to September 2020, 49 healthy children, including 26 males and 23 females aged $0-15$, who were examined at the Children's Hospital of Nanjing Medical University, were enrolled. This study also included a contemporaneous cohort of 22 adult volunteers who had a health examination and were aged 27 72. At the same time, 40 patients diagnosed with sepsis or $\mathrm{SAOD}^{11,12}$ in PICU were also selected. This study was conducted in accordance with the Declaration of Helsinki II and approved by the Medical Institutional Review Board of the Children's Hospital of Nanjing Medical University (approval No. 202008056-1). Informed consent was obtained before the study.A written informed consent was obtained from all participants, a parent or legal guardian of the children provided informed consent. 


\section{Detection of Indicators}

On the first day of the diagnosis of sepsis and SAOD, $2 \mathrm{~mL}$ of peripheral blood was collected from each child in EDTA anticoagulant tubes. After resting for 1.5 hours at room temperature, the upper serum layer was retained after centrifugation at $3000 \mathrm{R} /$ minute for 15 minutes and stored in a $-80{ }^{\circ} \mathrm{C}$ freezer for further use. Blood routine, blood biochemistry, and other tests were performed at the same time.

\section{Elisa}

Serum ACE2 levels were measured by enzyme-linked immunosorbent assay. The procedures were performed strictly according to the kit instructions. These kits were purchased from Boster Biological Technology Co, code EK0997. The microplate reader was manufactured by Thermo Fisher Inc.

\section{Statistical Analysis}

Distributions of variables were reported as the percentage. The mean \pm standard deviation (normal distribution) and the interquartile range were used when the data was not normally distributed [M, (P25 P75)]. Chisquare or Fisher's exact tests were used to analyze categorical variables, and a Mann-Whitney $U$-test was used to analyze continuous variables. The age-related differences between the same sexes were analyzed using a one-way analysis of variance (ANOVA) test, followed by Tukey's multiple comparison test. Sexrelated differences between the same ages were analyzed using T-tests. Univariate analysis with the Cox proportional-hazards model was utilized to analyze the factors that influenced the outcome of patients with SAOD. Receiver operating characteristic (ROC) analysis was used to establish the appropriate cutoff points for the ACE2 and D-dimer and to assess the sensitivity ( $\mathrm{Sn}$ ) and specificity $(\mathrm{Sp})$ of the predictors for SAOD. We also examined test parameters, including the area under the ROC curve (AUROC). A P-value of less than 0.05 (P $<$ $0.05)$ was considered statistically significant. Statistical analyses were performed with SPSS software (version 17.0, SPSS, Inc., Chicago, IL, USA) and GraphPad Prism 7 software.

\section{Results}

\section{Effects of Age on ACE2 Expression in Mouse Lung Tissues}

Quantitative analyses of ACE2 expression in mouse lung tissues were conducted via Western blotting. An immune response band of approximately $120 \mathrm{kDa}$ was detected. ACE2 expression differed between different age groups (Figure 1). ACE2 expression was high in the neonatal period and significantly low during childhood and adulthood in both females and males. On comparing with the newborns, ACE2 level in children decreased by approximately $54 \%$ in females $(\mathrm{P}<0.01)$ and $39 \%$ in males $(\mathrm{P}<$ 0.01). Adult ACE2 levels also showed an approximately $60 \%$ decrease in females $(\mathrm{P}<0.01)$ and $44 \%$ in males $(\mathrm{P}<$ $0.01)$. In the middle-aged cohort, ACE2 expression was restored to a level as high as that in the newborn cohort.
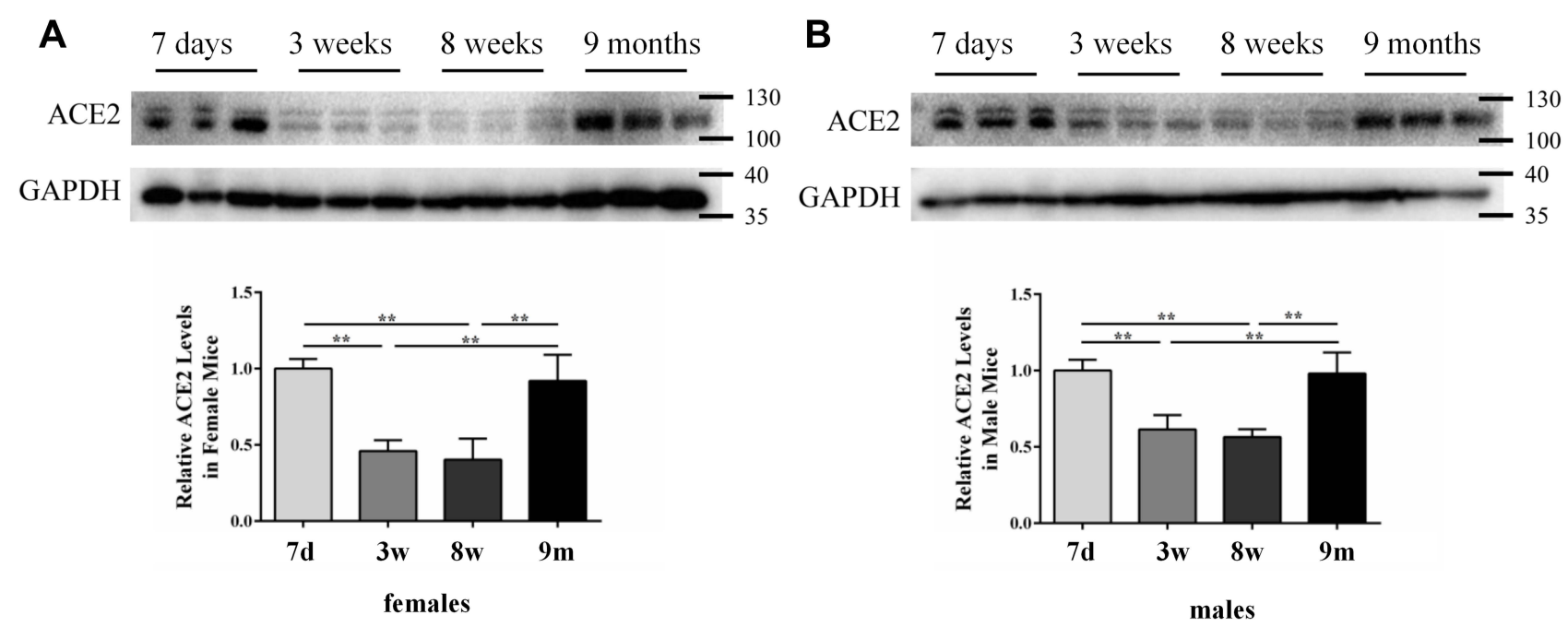

Figure I ACE2 expression in mouse lung tissues measured via Western blotting: (A) females and (B) males. GAPDH was used as a loading control. Values are represented as mean $\pm \mathrm{SD}(\mathrm{n}=3)$. The sizes of the molecular weight markers are shown on the right-hand side, representing $130 \mathrm{kDa}, 100 \mathrm{kDa}, 40 \mathrm{kDa}$, and $35 \mathrm{kDa}$ proteins. $* *, P<0.01$. 


\section{Effects of Gender on ACE2 Expression in Mouse Lung Tissues}

The results also showed no differences between females and males belonging to various age groups (Figure 2). Results of immunohistochemical analysis also suggested some changes in the expression of ACE2 protein between different age groups and sexes (Figure 3).

\section{Expression of ACE2 in Serum of Healthy Subjects}

When the ACE2 concentration was examined in the serum of healthy children as well as adults, there were no significant gender differences among the children in each age group (Figure 4). There were differences in the expression of ACE2 in different age groups, and infants younger than one year had a significantly higher concentration of ACE2 in serum and enhanced susceptibility compared with those
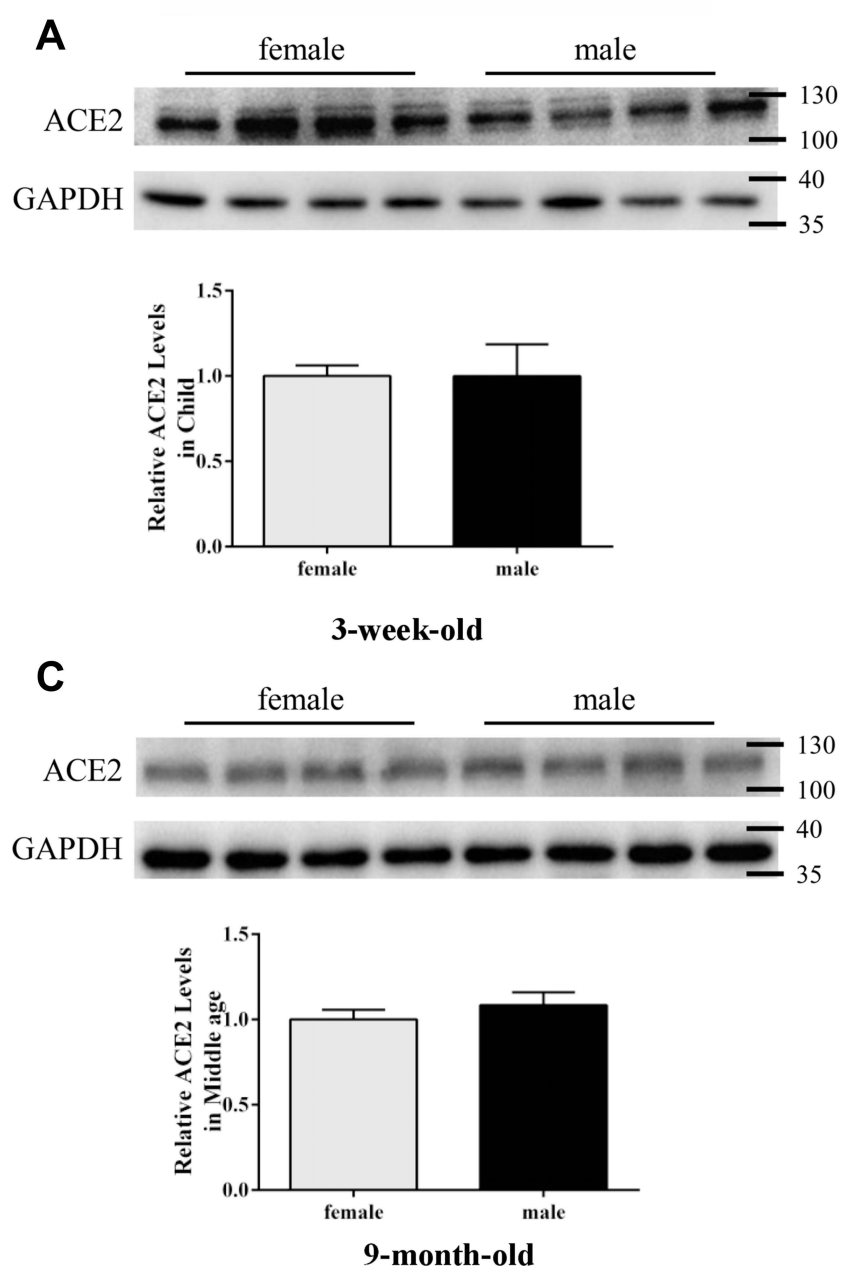

aged 6-10 years (school age), or 11-15 years (adolescence), as well as those in the adult group $(\mathrm{P}<0.05)$. The rest of the inter-group comparisons were not statistically significant.

\section{Demographics and Clinical Presentation of Children with Sepsis}

In this study, 40 children (17 girls, 23 boys, 20 under one year, 18 over one year) were diagnosed with sepsis. Fever $(75 \%)$, drowsiness $(25.0 \%)$, and vomiting $(22.5 \%)$ were major symptoms of sepsis in children. Clinical symptom distribution in different age groups was not statistically significant (Table 1).

\section{Analysis of Clinical Indicators in Children with Sepsis}

Among all patients with sepsis, 15 were SAOD (ten males, five females, ten aged under one, five aged over one). Neither age distribution nor gender was
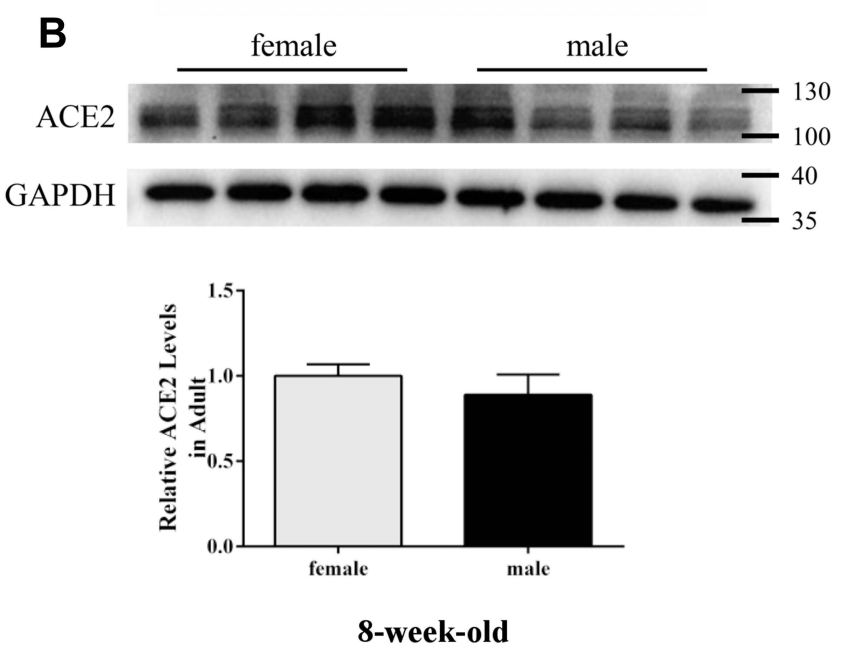

Figure 2 ACE2 expression in mouse lung tissues by Western blotting: (A) 3-week-old, (B) 8-week-old, (C) 9-month-old. GAPDH was used as a loading control. Values are represented as mean \pm SD $(n=4)$. The sizes of the molecular weight markers are shown on the right-hand side, representing $130 \mathrm{kDa}$, $100 \mathrm{kDa}$, $40 \mathrm{kDa}$, and $35 \mathrm{kDa}$ proteins. 


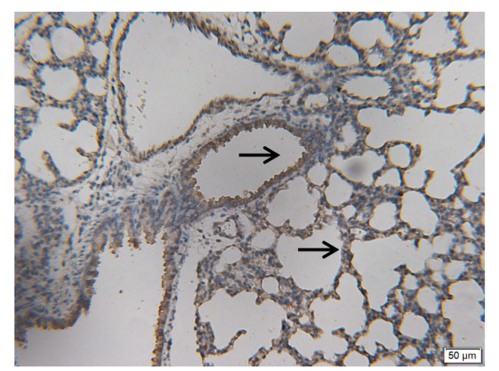

\section{7-day-old}

female
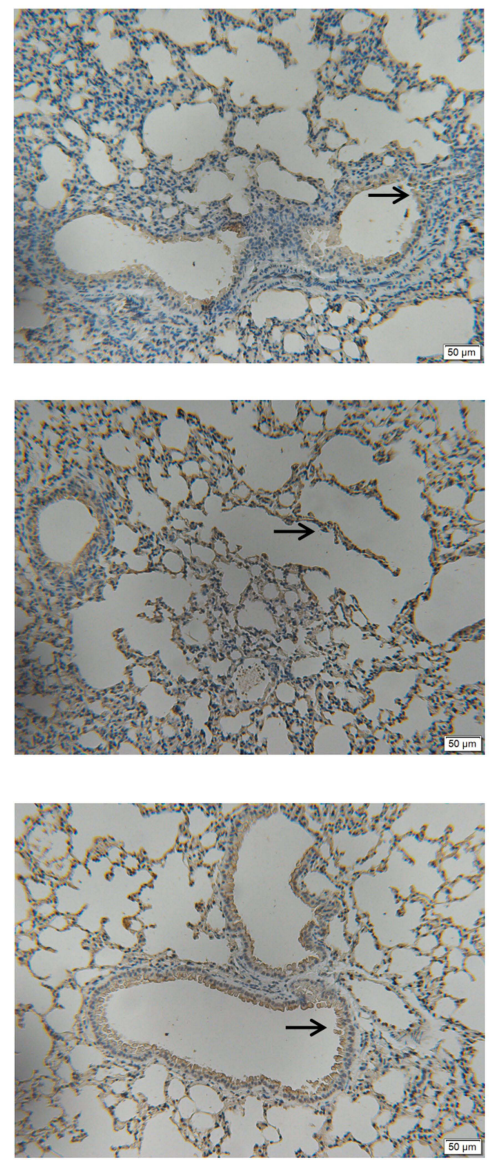

male
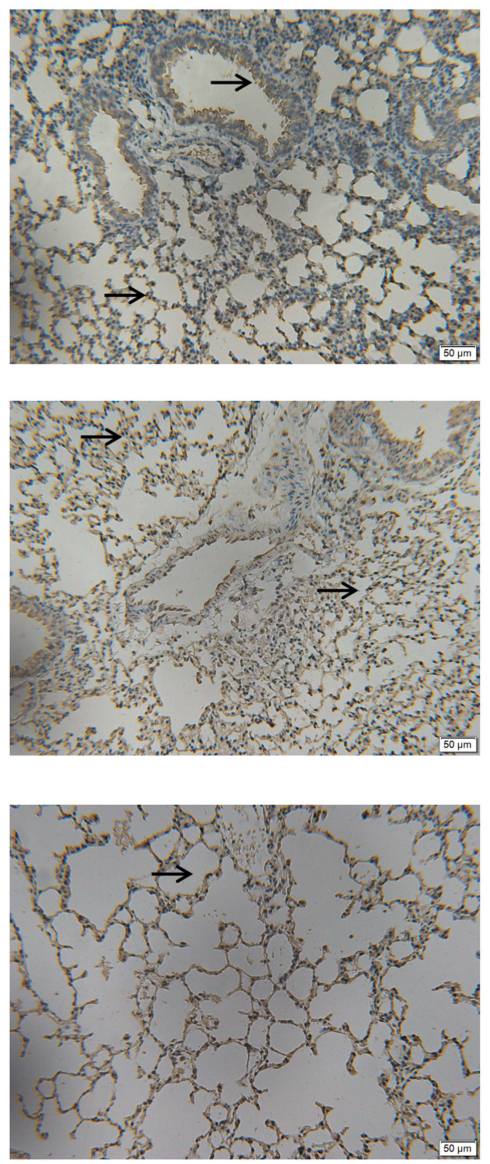

\section{3-week-old}

8-week-old

\section{9-month-old}

Figure 3 ACE2 expression in mouse lung tissues: as measured via immunohistochemical staining, brownish-yellow indicates the presence of ACE2 expression. Black arrow indicates that ACE2 brown staining deposition is mainly located in bronchial epithelium and alveolar epithelium. $(\times 200)$.

significantly different between the SAOD groups $(\mathrm{P}=0.332$ and $\mathrm{P}=0.512)$ (Table 2). Fever $(66.7 \%)$, drowsiness $(33.3 \%)$, and skin rashes $(26.7 \%)$ were the most common presenting symptoms in children with SAOD. Convulsions were more common in the SAOD group than the sepsis group, with statistical significance $(\mathrm{P}=0.046)$.

Table 3 shows the differences in laboratory data between sepsis, SAOD, and clinical indices, including routine blood, liver function, renal function, electrolytes, and cardiac enzyme profiles, reflecting the severity of the disease to some extent. According to Cox proportionalhazards regression analysis, serum APTT,

(A) dimer, LDH, PCT, and ACE2 in the sepsis and SAOD groups were statistically significant $(\mathrm{P}<$ $0.05)$ and were related to an increased risk of SAOD (Table 4). 

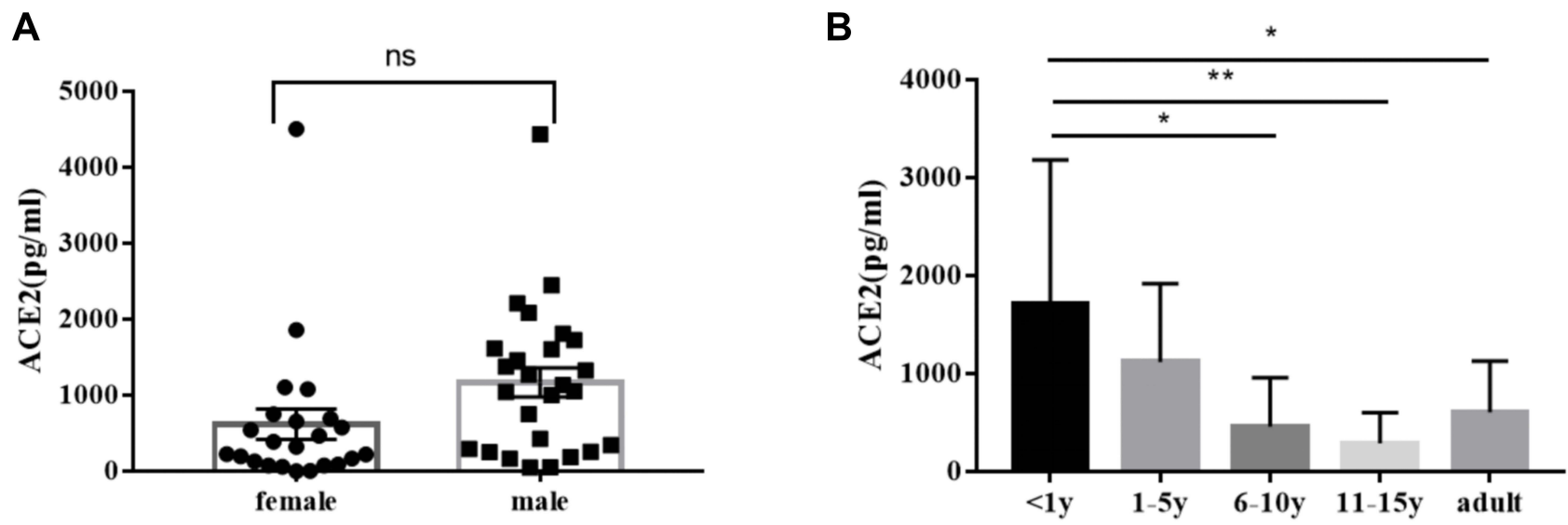

Figure 4 ACE2 concentration in serum of healthy individuals $(\mathrm{pg} / \mathrm{mL})$ : $(\mathbf{A})$ comparison of $A C E 2$ among children of different gender (ns $P>0.05)(\mathbf{B})$ difference of $A C E 2$ in serum of children of different age groups as well as adults $(* P<0.05, * *, P<0.01)$.

\section{Characteristic Analysis of SAOD Predictors}

The significant increase of ACE2 expression in the SAOD group can be used as a risk factor for predicting SAOD. The correlation analysis between ACE2 and risk factor indicators in patients with sepsis (Table 5) found that there was a positive correlation between ACE2 and D-dimer $(\mathrm{P}<0.05)$. The ROC curve of the prediction SAOD (Figure 5) found that the AUROC for the ACE2 was 0.872 in the ROC characteristic curve in predicting SAOD. Theoptimal cutoff value of ACE2 was $1551.15 \mathrm{pg} /$ mL (sensitivity: 0.867; specificity: 0.680). The ROC curve for the prediction of the SAOD by D-dimer was also analyzed (Figure 6). The AUROC for the D-dimer was 0.792 . The optimalcutoff valuefor this D-dimerwas 984.5 U/L(sensitivity: 0.692; specificity: 0.875). When ACE2 $>1551.15 \mathrm{pg} / \mathrm{mL}$ and D-dimer $>984.5 \mathrm{U} / \mathrm{L}$, it suggested an increased risk of sepsis-associated organ dysfunction.

\section{Discussion}

ACE2 is one of the central enzymes of the reninangiotensin system (RAS), which regulates blood pressure, fluid and electrolyte balance, and vascular tone. ${ }^{13}$ Because of the global spread of two viral infections in 2003 and 2019 , scientists began to pay more attention to the expression and mechanism of ACE2 in the population. For example, Xie et al reported the characteristics of ACE2 expression in the lung tissues of both sexes of rats belonging to three age groups (adult, middle-aged, and elderly). Their results showed that a decreased ACE2 expression in the older group compared with that in the young adult group might be the leading cause of SARS incidence. ${ }^{14}$
Children of all ages were prone to be infected with COVID-19, and the gender difference was not statistically significant. The clinical manifestations of children with COVID-19 are generally not as serious as adults, but children, especially infants, are vulnerable to infection. ${ }^{15}$ In our research, the changes in serum ACE2 levels of different age groups, including some adults, were tested. The expression of serum ACE2 level in different age groups varies (Figure 4), and infants younger than one year had a significantly higher concentration of ACE2 in serum and enhanced susceptibility compared with those aged 6-10 (school age), 11-15 (adolescence), as well as those in the adult group $(\mathrm{P}<0.05)$. The rest of the inter-group comparisons were not statistically significant. Simultaneously, ACE2 protein expression in mouse lung tissues of different ages and sexes was investigated. The four different age groups (newborn, child, adult, and middle-aged) were evaluated, and two main findings were obtained: 1) ACE2 expression in the lungs of both female and male mice showed noticeable age-specific dynamic changes. These were mainly expressed at high levels in the neonatal period, decreased during childhood and adulthood periods, and significantly increased during the middle-aged period (Figure 1) and (Figure 3). 2) There were no differences between the sexes (Figure 2). The above results suggest that the expression of ACE2 tends to be higher at younger ages, especially in infants and young children, and the susceptibility to infection is significantly enhanced. We need to pay more attention and be vigilant.

In recent years, evidence ${ }^{16}$ has shown the physiological and pathological effects of ACE2 in the cardiovascular, renal, and respiratory systems. Studies ${ }^{17}$ have shown that 
Table I Demographics and Clinical Presentation of the Patients with Sepsis

\begin{tabular}{|c|c|c|c|c|c|c|c|}
\hline \multirow[t]{2}{*}{ Variables } & \multicolumn{2}{|c|}{$\begin{array}{c}\text { Total } \\
(n=40)\end{array}$} & \multicolumn{2}{|c|}{$\begin{array}{l}<1 \text { Year } \\
(n=22)\end{array}$} & \multicolumn{2}{|c|}{$\begin{array}{l}>\text { I Year } \\
(n=18)\end{array}$} & \multirow[t]{2}{*}{$P$ value } \\
\hline & $\mathbf{N}$ & $\%$ & $\mathbf{N}$ & $\%$ & $\mathbf{N}$ & $\%$ & \\
\hline \multicolumn{8}{|l|}{ Gender } \\
\hline Female & 17 & 42.5 & 12 & 54.5 & 5 & 27.8 & 0.116 \\
\hline Male & 23 & 57.5 & 10 & 45.5 & 13 & 72.2 & \\
\hline \multicolumn{8}{|l|}{ Fever } \\
\hline Yes & 33 & 75.0 & 17 & 77.3 & 16 & 88.9 & 0.427 \\
\hline \multicolumn{8}{|l|}{ Cough } \\
\hline Yes & 6 & 15.0 & 3 & 13.6 & 3 & 16.7 & 1.000 \\
\hline \multicolumn{8}{|l|}{ Vomit } \\
\hline Yes & 9 & 22.5 & 7 & 31.2 & 2 & II.I & 0.149 \\
\hline \multicolumn{8}{|l|}{ Diarrhea } \\
\hline Yes & 3 & 7.5 & 2 & 9.1 & I & 5.6 & 1.000 \\
\hline \multicolumn{8}{|l|}{ Drowsiness } \\
\hline Yes & 10 & 25.0 & 8 & 36.4 & 2 & II.I & 0.082 \\
\hline \multicolumn{8}{|l|}{ Skin rashes } \\
\hline Yes & 5 & 12.5 & 2 & 9.1 & 3 & 16.7 & 0.642 \\
\hline \multicolumn{8}{|l|}{ Anhelation } \\
\hline Yes & 4 & 10.0 & 3 & 4.5 & 1 & 5.6 & 0.613 \\
\hline \multicolumn{8}{|l|}{ Convalsion } \\
\hline Yes & 3 & 7.5 & 2 & 9.1 & I & 5.6 & 1.000 \\
\hline \multicolumn{8}{|l|}{$\begin{array}{l}\text { full-term normal } \\
\text { delivery }\end{array}$} \\
\hline Yes & 23 & 57.5 & 12 & 54.5 & 11 & 61.1 & 1.000 \\
\hline \multicolumn{8}{|l|}{ First birth (GIPI) } \\
\hline Yes & 17 & 42.5 & 10 & 45.5 & 7 & 38.9 & 0.755 \\
\hline $\begin{array}{l}\text { breast feeding } \\
\quad \text { Yes }\end{array}$ & 34 & 85.0 & 18 & 81.8 & 16 & 88.9 & 0.673 \\
\hline
\end{tabular}

Notes: Fisher's Exact Test, Exact Sig.(2-sided).

ACE2 receptors are clearly expressed in nasal cavity epithelial cells, lung type 2 alveolar cells, the heart, liver, kidney, and gastrointestinal tract. During SARS-CoV-2 infection, ACE2-expressing tissues become direct targets, and severe cases can lead to multiple organ failure, sepsis, and death. Our results revealed several factors that may predict sepsis-associated organ dysfunction. These include convulsion, ACE2, and PCT. Moreover, increased ALT, AST, DB, APTT, D-dimer, increased levels of myocardial enzymes CKMB, and LDH tests were important factors that helped us detect organ dysfunction in these patients. Finally, we performed a Cox proportional-hazards
Table 2 Comparison of the Clinical Presentations of Patients with Sepsis and SAOD

\begin{tabular}{|c|c|c|c|c|c|}
\hline \multirow[t]{2}{*}{ Variables } & \multicolumn{2}{|c|}{$\begin{array}{l}\text { Sepsis } \\
(n=25)\end{array}$} & \multicolumn{2}{|c|}{$\begin{array}{l}\text { SAOD } \\
(n=15)\end{array}$} & \multirow[t]{2}{*}{$P$ value } \\
\hline & $\mathbf{N}$ & $\%$ & $\mathbf{N}$ & $\%$ & \\
\hline \multicolumn{6}{|l|}{ Gender } \\
\hline Female & 12 & 48.0 & 5 & 33.3 & 0.512 \\
\hline Male & 13 & 52.0 & 10 & 66.7 & \\
\hline \multicolumn{6}{|l|}{ Age } \\
\hline$<$ lyear & 12 & 48.0 & 10 & 66.7 & 0.332 \\
\hline$>$ lyear & 13 & 52.0 & 5 & 33.3 & \\
\hline \multicolumn{6}{|l|}{ Fever } \\
\hline Yes & 23 & 92.0 & 10 & 66.7 & $0.08 I$ \\
\hline \multicolumn{6}{|l|}{ Cough } \\
\hline Yes & 3 & 12.0 & 3 & 20.0 & 0.654 \\
\hline \multicolumn{6}{|l|}{ Vomit } \\
\hline Yes & 6 & 24.0 & 3 & 20.0 & 1.000 \\
\hline \multicolumn{6}{|l|}{ Diarrhea } \\
\hline Yes & 2 & 8.0 & I & 6.7 & 1.000 \\
\hline \multicolumn{6}{|l|}{ Drowsiness } \\
\hline Yes & 5 & 20.0 & 5 & 33.3 & 0.457 \\
\hline \multicolumn{6}{|l|}{ Skin rashes } \\
\hline Yes & I & 4.0 & 4 & 26.7 & 0.056 \\
\hline \multicolumn{6}{|l|}{ Anhelation } \\
\hline Yes & I & 4.0 & 3 & 20.0 & 0.139 \\
\hline \multicolumn{6}{|l|}{ Convalsion } \\
\hline Yes & 0 & 0.0 & 3 & 20.0 & $0.046 *$ \\
\hline \multicolumn{6}{|l|}{ Full-term normal delivery } \\
\hline Yes & 14 & 63.6 & 9 & 60.0 & 1.000 \\
\hline \multicolumn{6}{|l|}{ First birth (GIPI) } \\
\hline Yes & II & 44.0 & 6 & 40.0 & 1.000 \\
\hline \multicolumn{6}{|l|}{ Breast feeding } \\
\hline Yes & 22 & 88.0 & 12 & 80.0 & 0.654 \\
\hline
\end{tabular}

Notes: Fisher's Exact Test, Exact Sig.(2-sided), ${ }^{*}<0.05$.

Abbreviation: SAOD, sepsis-associated organ dysfunction.

regression analysis and found that APTT, D-dimer, LDH, PCT, and ACE2 were important factors that predicted sepsis-associated organ dysfunction. Correlation analysis between ACE2 and these risk factor indicators showed that the level of D-dimer is positively correlated with ACE2 ( $\mathrm{r}$ $=0.514, \mathrm{P}<0.001)$. Some researchers believe that patients with COVID-19, especially severely ill patients, have a higher risk of thrombosis. D-dimer can be increased in $50 \%$ of patients with COVID-19, and the degree of 
Table 3 Comparison of the Laboratory Tests of Patients with Sepsis and SAOD

\begin{tabular}{|c|c|c|c|c|c|c|c|c|}
\hline \multirow[t]{2}{*}{ Variables } & \multicolumn{3}{|c|}{ Sepsis(n=25) } & \multicolumn{3}{|c|}{ SAOD $(n=15)$} & \multirow[b]{2}{*}{$t / Z$} & \multirow[t]{2}{*}{$P$ value } \\
\hline & $\mathbf{N}$ & Mean & SD & $\mathbf{N}$ & Mean & SD & & \\
\hline WBC $\left(\times 10^{9} / \mathrm{L}\right)$ & 24 & 14.79 & 11.70 & 15 & 13.75 & 9.96 & 0.286 & 0.776 \\
\hline $\mathrm{Hb}(\mathrm{g} / \mathrm{L})$ & 25 & 104.4 & 20.46 & 15 & 99.73 & 39.85 & 0.425 & 0.676 \\
\hline CRP (mg/L) & 20 & 56.45 & 49.05 & 15 & 77.73 & 68.22 & -1.075 & 0.290 \\
\hline $\operatorname{PLT}\left(\times 10^{9} / \mathrm{L}\right)$ & 25 & 304.20 & $|47.5|$ & 15 & 224.60 & 179.04 & 1.525 & 0.136 \\
\hline $\operatorname{ALB}(g / L)$ & 25 & 37.49 & 5.12 & 15 & 33.13 & 9.88 & 1.588 & 0.129 \\
\hline $\mathrm{GLO}(\mathrm{g} / \mathrm{L})$ & 25 & \multicolumn{2}{|c|}{$20.30(18.45 \sim 22.95)$} & 15 & \multicolumn{2}{|c|}{$19.40(16.10 \sim 22.70)$} & -0.321 & 0.748 \\
\hline ALT (U/L) & 25 & \multicolumn{2}{|c|}{$12.00(9.00 \sim 24.00)$} & 15 & \multicolumn{2}{|c|}{$63.00(26.00 \sim 201.00)$} & -3.859 & $0.000 *$ \\
\hline AST (U/L) & 25 & \multicolumn{2}{|c|}{$23.00(19.00 \sim 38.00)$} & 15 & \multicolumn{2}{|c|}{$72.00(38.00 \sim 177.00)$} & -2.725 & $0.006 *$ \\
\hline $\mathrm{DB}(\mathrm{mmol} / \mathrm{L})$ & 25 & \multicolumn{2}{|c|}{$2.50(2.00 \sim 3.95)$} & 15 & \multicolumn{2}{|c|}{$9.00(2.30 \sim 13.10)$} & -2.222 & $0.026 *$ \\
\hline BUN (mmol/L) & 25 & \multicolumn{2}{|c|}{$2.90(2.45 \sim 4.43)$} & 15 & \multicolumn{2}{|c|}{$5.08(2.80 \sim 9.40)$} & -1.733 & 0.083 \\
\hline Creatinine $(\mathrm{mmol} / \mathrm{L})$ & 25 & \multicolumn{2}{|c|}{$26.00(20.20 \sim 46.50)$} & 14 & \multicolumn{2}{|c|}{$23.00(16.75 \sim 50.58)$} & -0.747 & 0.455 \\
\hline PT & 24 & \multicolumn{2}{|c|}{$12.70(|| .58 \sim 13.35)$} & 13 & \multicolumn{2}{|c|}{$13.10(12.15 \sim 18.30)$} & -1.273 & 0.203 \\
\hline APTT & 24 & \multicolumn{2}{|c|}{$34.95(32.40 \sim 39.90)$} & 13 & \multicolumn{2}{|c|}{$39.60(34.55 \sim 70.70)$} & -2.212 & $0.027^{*}$ \\
\hline D-dimer(U/L) & 24 & \multicolumn{2}{|c|}{$358.50(I 74.00 \sim 744.50)$} & 13 & \multicolumn{2}{|c|}{$|28| .0(56 \mid .5 \sim 5662.0)$} & -2.895 & $0.004 *$ \\
\hline Potassium (mmol/L) & 25 & 4.68 & 0.82 & 15 & 4.89 & 1.27 & -0.656 & 0.515 \\
\hline Sodium (mmol/L) & 25 & $136.0 \mid$ & 3.76 & 15 & 134.30 & 8.08 & 0.911 & 0.368 \\
\hline Calcium (mmol/L) & 25 & \multicolumn{2}{|c|}{$2.37(2.21 \sim 2.45)$} & 15 & \multicolumn{2}{|c|}{$2.09(1.84 \sim 2.40)$} & -1.859 & 0.063 \\
\hline $\mathrm{LDH}(\mathrm{U} / \mathrm{L})$ & 24 & \multicolumn{2}{|c|}{$298.50(238.25 \sim 382.50)$} & 15 & \multicolumn{2}{|c|}{$560.0(313.0 \sim 1191.0)$} & -2.627 & $0.009 *$ \\
\hline CK(U/L) & 25 & \multicolumn{2}{|c|}{$62.00(22.00 \sim 108.50)$} & 15 & \multicolumn{2}{|c|}{$71.00(39.00 \sim 204.00)$} & -1.355 & 0.175 \\
\hline CKMB(U/L) & 25 & \multicolumn{2}{|c|}{$22.00(16.00 \sim 29.50)$} & 15 & \multicolumn{2}{|c|}{$43.00(17.00 \sim 104.00)$} & -1.986 & $0.047^{*}$ \\
\hline $\mathrm{PCT}(\mathrm{ng} / \mathrm{mL})$ & 25 & \multicolumn{2}{|c|}{$0.79(0.24 \sim 2.91)$} & 15 & 19.7 & $5.10)$ & -2.585 & $0.010 *$ \\
\hline NT-proBNP (pg/mL) & 9 & 80.00 & $91.50)$ & 14 & 224.0( & (I.75) & -1.072 & 0.284 \\
\hline ACE2 $(\mathrm{pg} / \mathrm{mL})$ & 25 & 471.00 & 2507.9) & 15 & 4494.0 & 13329) & -3.143 & $0.002 *$ \\
\hline
\end{tabular}

Notes: *Statistically significant according to the Mann-Whitney U-test.

Abbreviations: IQR, interquartile range, $M\left(P_{25} \sim P_{75}\right)$; WBC, white blood count; $C R P$, C-reactive protein; $C K$, creatine phosphokinase; $C K M B$, creatine phosphokinase-MB; AST, aspartate aminotransferase; ALT, alanine aminotransferase; BUN, blood urea nitrogen; PCT, procalcitonin; NT-proBNP, N-terminal prohormone of brain natriuretic peptide; SAOD, sepsis-associated organ dysfunction; ACE2, angiotensin-converting enzyme 2.

Table 4 Analysis of Factors Influencing SAOD That Was Performed in Patients with Sepsis

\begin{tabular}{|l|c|c|c|c|c|c|}
\hline Variables & $\boldsymbol{\beta}$ & S.E. & Wald & $\operatorname{Exp}(\boldsymbol{\beta})$ & $95 \%$ CI for $\operatorname{Exp}(\boldsymbol{\beta})$ & $\boldsymbol{P}$ value \\
\hline D-dimer & 0.015 & 0.010 & 2.017 & 1.105 & $1.000 \sim 1.002$ & $0.006^{*}$ \\
LDH & -0.012 & 0.005 & 5.136 & 0.988 & $0.979 \sim 0.998$ & $0.023^{*}$ \\
PCT & 0.135 & 0.050 & 7.272 & 1.144 & $1.038 \sim 1.262$ & $0.007^{*}$ \\
ACE2 & 0.000 & 0.000 & 5.935 & 1.000 & $1.000 \sim 1.000$ & $0.015^{*}$ \\
APTT & 0.068 & 0.027 & 6.555 & 1.071 & $1.016 \sim 1.128$ & $0.010^{*}$ \\
\hline
\end{tabular}

Notes: *Statistically significant according to a Cox proportional-hazards regression analysis.

Abbreviations: IQR, interquartile range; SAOD, sepsis-associated organ dysfunction; Exp( $\beta)$, Hazard Ratio; $95 \% \mathrm{Cl}$ for $\operatorname{Exp}(\beta)$, Univariate $\mathrm{Analysis} 95 \% \mathrm{Cl}$.

Table 5 Correlation Analysis Between ACE2 and Risk Factor Indicators in Patients with Sepsis

\begin{tabular}{|c|c|c|c|c|c|c|c|c|}
\hline \multirow[t]{2}{*}{ Variables } & \multicolumn{2}{|c|}{ D-dimer } & \multicolumn{2}{|c|}{ LDH } & \multicolumn{2}{|c|}{ РCT } & \multicolumn{2}{|c|}{ APTT } \\
\hline & $\mathbf{r}$ & $p$ & $r$ & $p$ & $\mathbf{r}$ & $p$ & $\mathbf{r}$ & $p$ \\
\hline ACE2 & 0.514 & $0.001 *$ & 0.070 & 0.681 & 0.284 & 0.080 & 0.164 & 0.311 \\
\hline
\end{tabular}

Notes: *Statistically significant according to a Spearman correlation analysis, Sig.(2-sided), $\mathrm{p}<0.05$. 


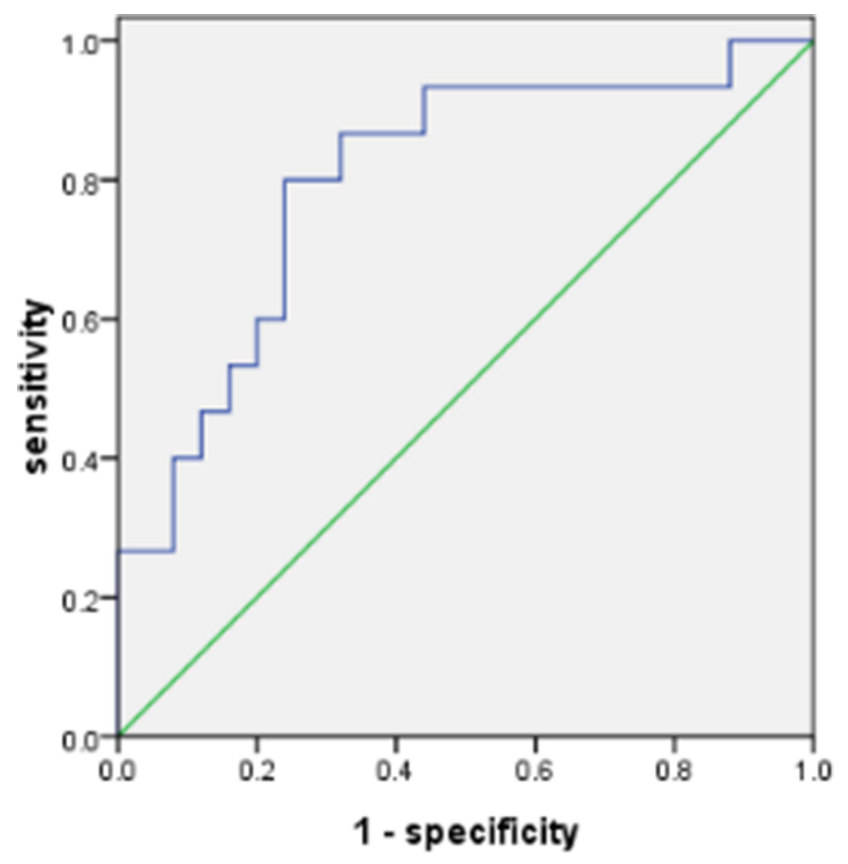

Figure 5 Receiver operating characteristic curve for ACE2 in predicting sepsisassociated organ dysfunction. The area under the curve was 0.800 . The best cutoff value for ACE2 was $1551.15 \mathrm{pg} / \mathrm{mL}$ (sensitivity: 0.867 ; specificity: 0.680 ).

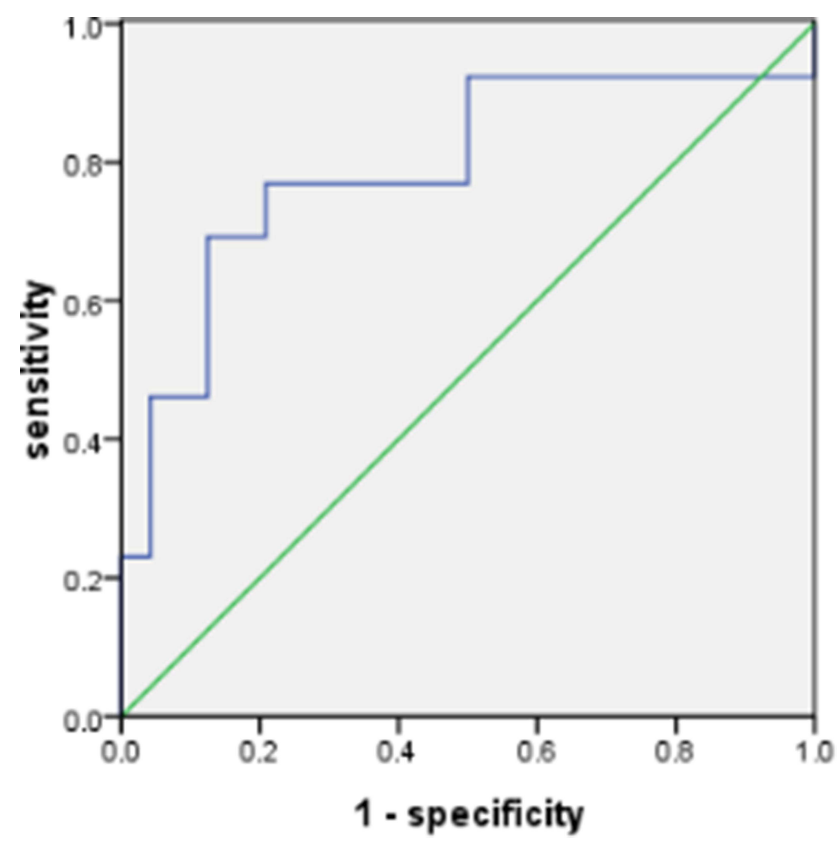

Figure 6 Receiver operating characteristic curve for the D-dimer in predicting sepsis-associated organ dysfunction. The area under the curve was 0.792 . The best cutoff value for the D-dimer was $984.5 \mathrm{U} / \mathrm{L}$ (sensitivity: 0.692 ; specificity: 0.875 ).

fibrinogen degradation products (FDP) and D-dimer in patients who are severely ill or who have died is significantly higher than that in mild cases. ${ }^{18,19}$ In patients with COVID-19, the level of D-dimer of $>1 \mathrm{mg} / \mathrm{L}$ is directly related to the prognosis. ${ }^{20}$ Sepsis patients have abnormal blood coagulation function, which is mainly manifested as an abnormal increase in D-dimer. This is associated with multiple organ failure and increased mortality. ${ }^{21,22}$ Our study showed significant differences in ACE2 and D-dimer between the patients with sepsis and SAOD. Moreover, our results suggest that the most appropriate cutoff value of the ACE2 level in predicting SAOD was $1551.15 \mathrm{pg} / \mathrm{mL}$, and the D-dimer was $984.5 \mathrm{U} / \mathrm{L}$.

This article has some limitations. First, it only explores the expression characteristics of ACE2 in lung tissues of different ages and has not studied the expression of ACE2 in multiple organs. Second, this article explored the risk prediction of ACE2 and D-dimer on SAOD, and further exploration of the pathogenesis of ACE2 and D-dimer in SAOD is needed.

In summary, the expression of ACE2 expression varied in different age groups. It tends to be higher in infants and young children. This result suggests that young children are more susceptible to infection. Moreover, a cutoff value for the ACE2 level $>1551.15 \mathrm{pg} / \mathrm{mL}$ and D-dimer $>984.5$ $\mathrm{U} / \mathrm{L}$ should be considered a warning sign of infectionassociated organ dysfunction and guide the clinician in evaluating the care of the patient's multiple organ function.

\section{Ethics Approval}

Principles of Laboratory Animal Care' (NIH Publication Vol 25, No. 28 revised 1996; http://grants.nih.gov/grants/ guide/notice-files/not96-208. html) were followed, as well as specific national laws (eg the current version of the German Law on the Protection of Animals) where applicable.

\section{Funding}

This study was funded by the National Natural Science Foundation of Jiangsu Province (no. BK20170147) and the Nanjing Medical Science and Technique Development Foundation (no. YKK16181).

\section{Disclosure}

The authors report no conflicts of interest in this work.

\section{References}

1. Paul M, Poyan Mehr A, Kreutz R. Physiology of local renin-angiotensin systems. Physiol Rev. 2006;86(3):747-803. doi:10.1152/physrev.00036.2005

2. Imai Y, Kuba K, Rao S, et al. Angiotensin-converting enzyme 2 protects from severe acute lung failure. Nature. 2005;436 (7047):112-116. doi:10.1038/nature03712 
3. Ramchand J, Patel SK, Kearney LG, et al. Plasma ACE2 activity predicts mortality in aortic stenosis and is associated with severe myocardial fibrosis. JACC Cardiovasc Imaging. 2020;13 (3):655-664. doi:10.1016/j.jcmg.2019.09.005

4. Wijnant SRA, Jacobs M, Van Eeckhoutte HP, et al. Expression of ACE2, the SARS-CoV-2 Receptor, in Lung Tissue of Patients With Type 2 Diabetes. Diabetes. 2020;69(12):2691-2699. doi:10.2337/ db20-0669

5. Hoffmann M, Kleine-Weber H, Schroeder S, et al. SARS-CoV-2 Cell Entry Depends on ACE2 and TMPRSS2 and Is Blocked by a Clinically Proven Protease Inhibitor. Cell. 2020;181(2):271-80 e8. doi:10.1016/j.cell.2020.02.052

6. Zhou P, Yang XL, Wang XG, et al. A pneumonia outbreak associated with a new coronavirus of probable bat origin. Nature. 2020;579 (7798):270-273. doi:10.1038/s41586-020-2012-7

7. Walls AC, Park YJ, Tortorici MA, Wall A, McGuire AT, Veesler D. Structure, Function, and Antigenicity of the SARS-CoV-2 Spike Glycoprotein. Cell. 2020;181(2):281-92 e6. doi:10.1016/j. cell.2020.02.058

8. Huang C, Wang Y, Li X, et al. Clinical features of patients infected with 2019 novel coronavirus in Wuhan, China. Lancet. 2020;395 (10223):497-506. doi:10.1016/S0140-6736(20)30183-5

9. Wang $\mathrm{D}, \mathrm{Hu} \mathrm{B}, \mathrm{Hu} \mathrm{C}$, et al. Clinical Characteristics of 138 Hospitalized Patients With 2019 Novel Coronavirus-Infected Pneumonia in Wuhan, China. JAMA. 2020;323(11):1061-1069. doi:10.1001/jama.2020.1585

10. Chen N, Zhou M, Dong X, et al. Epidemiological and clinical characteristics of 99 cases of 2019 novel coronavirus pneumonia in Wuhan, China: a descriptive study. Lancet. 2020;395 (10223):507-513. doi:10.1016/S0140-6736(20)30211-7

11. Goldstein B, Giroir B, Randolph A. International Consensus Conference on Pediatric Sepsis International pediatric sepsis consensus conference: definitions for sepsis and organ dysfunction in pediatrics. Pediatr Crit Care Med. 2005;6(1):2-8. doi:10.1097/01. PCC.0000149131.72248.E6

12. Hattori Y, Hattori K, Suzuki T, Matsuda N. Recent advances in the pathophysiology and molecular basis of sepsis-associated organ dysfunction: novel therapeutic implications and challenges. Pharmacol Ther. 2017;177:56-66. doi:10.1016/j.pharmthera.2017.02.040.
13. Paul M, Poyan Mehr A, Kreutz R. Physiology of local renin-angiotensin systems. Physiol Rev. 2006;86(3):747-803. doi:10.1152/physrev.00036.2005

14. Xie X, Chen J, Wang X, Zhang F, Liu Y. Age- and gender-related difference of ACE2 expression in rat lung. Life Sci. 2006;78 (19):2166-2171. doi:10.1016/j.lfs.2005.09.038

15. Dong Y, Mo X, Hu Y, et al. Epidemiology of COVID-19 among children in china. Pediatrics. 2020;145(6). doi:10.1542/peds.20200702

16. Imai Y, Kuba K, Ohto-Nakanishi T, Penninger JM. Angiotensinconverting enzyme 2 (ACE2) in disease pathogenesis. Circ J. 2010;74(3):405-410. doi:10.1253/circj.cj-10-0045

17. Yan T, Xiao R, Lin G. Angiotensin-converting enzyme 2 in severe acute respiratory syndrome coronavirus and SARS-CoV-2: a double-edged sword? FASEB J. 2020;34(5):6017-6026. doi:10.1096/fj.202000782

18. Huang C, Wang Y, Li X, et al. Clinical features of patients infected with 2019 novel coronavirus in Wuhan, China. Lancet. 2020;395 (10223):497-506. doi:10.1016/S0140-6736(20)30183-5

19. Wang D, Hu B, Hu C, et al. Clinical Characteristics of 138 Hospitalized Patients With 2019 Novel Coronavirus-Infected Pneumonia in Wuhan, China. JAMA. 2020;323(11):1061-1069. doi:10.1001/jama.2020.1585

20. Zhou F, Yu T, Du R, et al. Clinical course and risk factors for mortality of adult inpatients with COVID-19 in Wuhan, China: a retrospective cohort study. Lancet. 2020;395(10229):1054-1062. doi:10.1016/S0140-6736(20)30566-3

21. Semeraro F, Ammollo CT, Caironi P, et al. D-dimer corrected for thrombin and plasmin generation is a strong predictor of mortality in patients with sepsis. Blood Transfus. 2020;18(4):304-311. doi:10.2450/2019.0175-19

22. Sharma A, Sikka M, Gomber S, Sharma S. Plasma Fibrinogen and D-dimer in Children With Sepsis: a Single-Center Experience. Iran J Pathol. 2018;13(2):272-275. doi:10.30699/ijp.13.2.272
Journal of Inflammation Research

\section{Publish your work in this journal}

The Journal of Inflammation Research is an international, peerreviewed open-access journal that welcomes laboratory and clinical findings on the molecular basis, cell biology and pharmacology of inflammation including original research, reviews, symposium reports, hypothesis formation and commentaries on: acute/chronic inflammation; mediators of inflammation; cellular processes; molecular mechanisms; pharmacology and novel anti-inflammatory drugs; clinical conditions involving inflammation. The manuscript management system is completely online and includes a very quick and fair peerreview system. Visit http://www.dovepress.com/testimonials.php to read real quotes from published authors. 